Article

\title{
Conventional, Partially Converted and Environmentally Friendly Farming in South Korea: Profitability and Factors Affecting Farmers' Choice
}

\author{
Saem Lee ${ }^{1, *}$, Trung Thanh Nguyen ${ }^{2}$, Patrick Poppenborg ${ }^{1}$, Hio-Jung Shin ${ }^{3}$ \\ and Thomas Koellner ${ }^{1}$ \\ 1 Faculty of Biology, Chemistry and Geosciences, University of Bayreuth, BayCEER, Bayreuth 95440, \\ Germany; patrick.poppenborg@uni-bayreuth.de (P.P.); thomas.koellner@uni-bayreuth.de (T.K.) \\ 2 Institute for Environmental Economics and World Trade, Leibniz University of Hannover, \\ Hannover 30167, Germany; thanh.nguyen@iuw.uni-hannover.de \\ 3 Department of Agricultural and Resource Economics, Kangwon National University, 1 Kangwondaehak-gil, \\ Chuncheon-si, Gangwon-do 24341, Republic of Korea; hiojung@kangwon.ac.kr \\ * Correspondence: Saem.Lee@uni-bayreuth.de; Tel.: +49-0921-55-4658; Fax: +49-0921-55-2334 \\ Academic Editor: Sean Clark \\ Received: 30 May 2016; Accepted: 15 July 2016; Published: 25 July 2016
}

\begin{abstract}
While organic farming is well established in Europe a nd USA, it is still catching up in Asian countries. The government of South Korea has implemented environmentally friendly farming that encompasses organic farming. Despite the promotion of environmentally friendly farming, it still has a low share in South Korea and partially converted farming has emerged in some districts of South Korea. However, the partially converted farming has not yet been investigated by the government. Thus, our study implemented a financial analysis to compare the annual costs and net returns of conventional, partially converted and environmentally friendly farming in Gangwon Province. The result showed that environmentally friendly farming was more profitable with respect to farm net returns. To find out the factors affecting the adoption of environmentally friendly farming, multinomial logistic regression was implemented. The findings revealed that education and subsidy positively and significantly influenced the probability of farmers' choice on partially converted and environmentally friendly farming. Farm size had a negative and significant relationship with only environmentally friendly farming. This study will contribute to future policy establishment for sustainable agriculture as recommended by improving the quality of fertilizers, suggesting the additional investigation associated with partially converted farmers.
\end{abstract}

Keywords: environmentally friendly farming; partial conversion; economic benefits; decision-making

\section{Introduction}

Agriculture creates benefits for humans by providing fiber, food and fuel. However, intensively managed farms have increased various adverse effects including soil degradation, biodiversity loss, water pollution and agro-chemical pollution. Due to heavily managed intensive farming targeting yield maximization, environmental concerns over negative externality of agricultural production have been increasing. Therefore, sustainable agriculture has been developed as the alternative under conservation of environmental quality and the scarcity of natural resources. One of the alternatives can be several advanced farming management practices such as organic, environmentally friendly and partially converted and low-pesticides farming.

Organic farming is one of the most widespread farming techniques that balance social, economic and environmental sustainability. Although there are many definitions of organic farming [1], it is generally defined that it avoids the use of synthetic chemical fertilizers and pesticides, and regulates 
the application of agriculture practices [2,3]. Organic farming emphasizes ecological processes, human health and renewable resources adapted to the local agricultural system [4]. Despite the contentious issue on economic and environmental effects, organic farming has the potential to reduce environmental pollution [5-7], with higher farm household income and benefits to rural economies [8,9]. Moreover, in response to consumer demand for healthy food products, many farmers are converting their production method from conventional to organic farming [10].

In contrast with other developed countries like those in the European Union, which have adopted strict organic farming, the government of South Korea has adopted environmentally friendly farming since 1999. Due to the more flexible regulations than those supporting organic farming in the European Union, environmentally friendly farming in South Korea includes organic, no-pesticide and low-pesticide farming [11]. While the use of chemical fertilizers and pesticides of organic farming is forbidden like in other developed countries, the no-pesticide farming standard in South Korea allows the use of a certain level of chemical fertilizers. The low-pesticide farming allowed the use of both a certain level of chemical fertilizers and synthetic pesticides was abolished in 2015 . The government of South Korea has implemented a long-term plan to promote environmentally friendly farming since 2000. The plan aimed to extend cultivated areas, to decrease the synthetic chemical inputs such as fertilizers and pesticides and to expand the organic products market [12]. This plan increased certified areas of environmentally friendly farming up to 172,674 ha cultivated by 160,628 farm households in 2011 . These produced and supplied $1,819,228$ tons of environmentally friendly agricultural products in 2011. The main cultivated products of environmentally friendly farming were vegetables (38.5\%), fruits $(23.8 \%)$, and cereal crops $(22.3 \%)$. The area of environmentally friendly cultivation was approximately $10 \%$ in 2011 [12]. However, organic agricultural area was only about 1.1\% in 2011 (Table S1), still accounting for a small proportion [11]. This is similar to the global organic agricultural land, accounting for approximately 1\% [13]. Although North America, Africa, and Asia are lagging behind Europe and Latin America that are leading the growth of organic farming, the proportion of land cultivated using organic farming method is still low all over the world [13].

In the context of the low adoption rate of organic farming all over the world, considerable research attention has been paid to economic differences between conventional and organic farming $[7,14]$. The differences between net returns and costs analyzed by previous studies show that organic farming can be profitable $[15,16]$. Considering higher willingness to pay for organic products and the price premium paid by consumers $[8,17]$, organic farming is more financially lucrative than conventional farming $[18,19]$. The majority of previous studies examined the driving forces leading to organic farming in conjunction with biophysical, institutional, socio-economic and political factors influencing farmers' choices [20-23]. In South Korea, a number of studies have contributed to the development of environmentally friendly farming including organic farming in the context of the production, consumption and distribution for environmentally friendly farming [24-26].

Furthermore, in South Korea, through only our field survey, it was observed that partially converted farmers existed. Partially converted organic farming has emerged in some countries, however, it is not allowed in some other countries which require compliance with rigorous regulations for organic farming in the various developmental paths [27]. The partially converted farming is defined so that farmers can decide to use only part of their land for organic production [28]. In other words, the partially converted farmers are using both conventional and environmentally friendly farming practices according to their own choices. They can become completely organic farmers in the near future, but are starting by implementing some organic practices now. Consequently, their farms are less than "half-organic". While previous studies shed light on the profitability of different types of farming, including partially converted farming in Europe and Canada [28,29], less is known for Asian countries. Only some studies in this important world region focus on environmentally friendly or organic farming $[30,31]$ and the issue of partially converted farming is not yet covered. The missing differentiation between fully and partially converted organic farming is certainly a limitation of current empirical studies on organic farming [8]. 
Therefore, the first objective of our research was to identify the profitability among different farming techniques; i.e., conventional farming (CF), partially converted farming (PCF) and environmentally friendly farming (EFF), hereafter abbreviated with CF, PCF and EFF respectively. The second objective was to examine the key factors influencing the adoption of farming techniques in South Korea. This paper draws crucial conclusions based on a detailed discussion of the financial analysis with descriptive statistics and multinomial logistic regressions. The findings and policy recommendations can make valuable contributions to development of policies to promote organic farming in South Korea and other Asian countries.

\section{Method}

\subsection{Study Area and Background}

This study was conducted in the Soyang catchment of Yanggu-Gun (Nam-Myeon, Yanggu-Eup and Haean-Myeon), Inje-Gun (Girin-Myeon, Nam-Myeon, Buk-Myeon, Sangnam-Myeon, Seohwa-Myeon and Inje-Eup) and Hongcheon-Gun (Nae-Myeon) in Gangwon Province, South Korea (Figure 1b). The study site was selected based on consideration of the low adoption level of organic farming in South Korea, as well as the potential hazard of water pollution within Soyang watershed from intensively managed practices in the Gangwon Province of South Korea. The Gangwon Province in South Korea plays a key role in protecting the water quality of the upper Soyang watershed, which provides water supplies to downstream residents of several, densely populated cities of South Korea. Accordingly, EFF has been promoted in the Gangwon Province, to improve the water quality in Soyang watershed, which comprises environmentally sensitive area. Despite the promotion of environmentally friendly farming by the local and central government, water quality issues coming from intensive farming activities in the area have been continued. Therefore, based on the low adoption rate of EFF and the desired reduction of water pollution from $\mathrm{CF}$, we selected the main environmentally sensitive area, the three districts in Gangwon Province of South Korea as our study area.

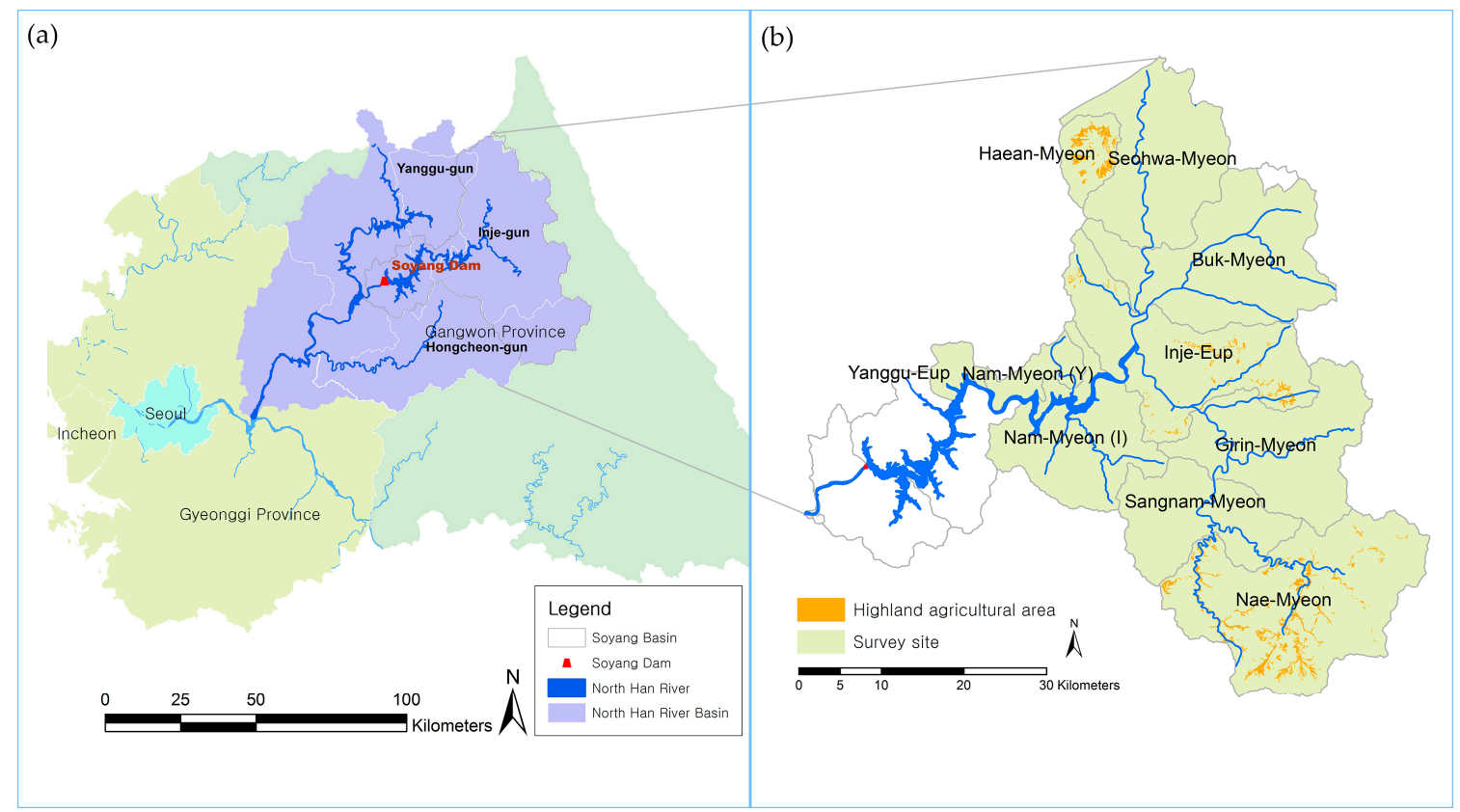

Figure 1. Location map of: (a) Soyang watershed in Gangwon Province; (b) three districts showing highland agricultural area.

The Gangwon Province of South Korea, which includes the catchment of the three districts, is located in the mountainous northeastern part of South Korea (latitude $37^{\circ} 02^{\prime} \mathrm{N}-38^{\circ} 37^{\prime} \mathrm{N}$ and 
longitudes $\left.127^{\circ} 05^{\prime} \mathrm{E}-129^{\circ} 22^{\prime} \mathrm{E}\right)$. The Gangwon Province occupies around $20,569 \mathrm{~km}^{2}$. The total agricultural area of the province was 109,496 ha which consists of rice paddies (41,086 ha) and field land (68,410 ha). The total population of farmers in the provin0ce was 191,922 in 2011 [32]. In 2011 the average farm size, from a total of 71,687 farm households in Gangwon Province, was 1.5 ha per farm, of which 0.57 ha was occupied by rice and 0.95 ha of field land, respectively. As of 2011, the total EFF cultivated farmland was 7962 ha with 5854 EFF farm households in this province; organic was 1976 ha and 1093 farm households, no-pesticide was 4899 ha and 3561 farm households, low-pesticide was 1088 ha and 1200 farm households [32]. The certified EFF area accounted for only about $4.6 \%$ of the whole of the certified areas in South Korea [26].

For this study, the three areas were selected within the watershed of Soyang Lake in Gangwon Province (Figure 1a). The Soyang watershed $\left(2694.35 \mathrm{~km}^{2}\right)$ is the largest reservoir and tributary located North of the Han River in South Korea. The watershed is important as one of the main drinking water sources of Seoul, capital of South Korea, and other metropolitan areas in South Korea. The residents in the downstream area of the watershed utilize the water resource overwhelmingly due to high population density of the capital area that shared $48.3 \%$ of the country's population in 2011. In other words, the water pollution in surrounding environmentally sensitive areas, especially in the selected area, is seriously affected by intensive farming, and can seriously damage fresh drinking water use of the citizens.

During the 2006 monsoon period, the water quality was seriously reduced brought by Typhoon "EWINER", resulting in high levels of turbidity (328NTU (Number of Transfer Units)), which was nearly four times the turbidity level observed the previous year. At that time, the sediment yields (865,062 ton/year) within the watershed were substantially higher from agricultural practices in the mountainous area. In order to protect the water quality of the Soyang watershed for the province, since 2006, selected areas have been designated as initial nonpoint pollution source management areas, with the aim of reducing sediment yields from agricultural practices in the mountainous areas of South Korea [33].

The three major regions causing the water quality problem from farming activities accounted for about $82.7 \%$ of the watershed in Gangwon Province [33]. The main areas of the Soyang watershed affecting from agricultural practices were Yanggu-Gun $\left(146.44 \mathrm{~km}^{2}\right)$, Inje-Gun $\left(1678.48 \mathrm{~km}^{2}\right)$ and Hongcheon-Gun $\left(447.83 \mathrm{~km}^{2}\right)$. The landscape of the catchment area is dominated in highland regions by upland fields. Out of the total highland farmland area (7313 ha) of South Korea, the majority of the highland upland areas were found in Yagngu-Gun $\left(143.97 \mathrm{~km}^{2}\right)$, Inje-Gun $\left(1636.32 \mathrm{~km}^{2}\right)$ and Hongcheon-Gun $\left(447.51 \mathrm{~km}^{2}\right)$ of the Province [33]. Regarding the water pollution associated with farming activities, the crucial problem identified was over-use of pesticides and fertilizers on steep slopes and at relatively high altitudes [34-36]. The main crops cultivated in the mountainous area were Chinese cabbage and radish, which rely heavily on chemical fertilizers and pesticides. In these areas, intensive agricultural practices with high concentrations of phosphorous and nitrogen, led to eutrophication of the reservoir $[37,38]$. This negatively affected the habitat of endangered species in the aquatic ecosystems of the watershed. Considering that the adverse effects could appear occasionally, although stable drinking water quality has been maintained in South Korea, there is potential for degradation of water quality from intensively managed farming activities still remaining in the districts during monsoon climate.

\subsection{Sampling of Farm Households and Data Collection}

Data were collected by face-to-face interviews. The survey period was between 19 March 2012 and 6 April 2012. The lists of residential farmers were received from local leaders and governmental staff after focus group meetings. During a pilot survey, we found that partially converted farmers existed between conventional and environmentally friendly farmers. Thus, stratified random sampling was selected from two farming techniques (CF and EFF) to three farming techniques (CF, PCF, and EFF). The sampling was applied to draw an estimated $7 \%$ sample size based on total population of farmers 
in three regions, due to time and budget constraints. Before the main survey of farm households, we contacted the farmers in the list by phone to check their production method and arrange the interviews from the contact lists. In addition, after the survey, in order to obtain more exact information on the survey, a gift was offered to the participants. Due to no responses and outliers in the key questions (Figures S1-S4), 218 farm households' interviews were analyzed from a total of 224 interviews. The data consisted finally of 85 conventional farmers, 65 partially converted farmers and 68 environmentally friendly farmers.

For the questionnaire, a pilot survey was carried out in order to check accuracy of the questionnaire and modify sentences to avoid misunderstanding. Through discussions with heads of the local farm households and governmental staff that were responsible for EFF, a semi-structured questionnaire was constructed. Based on feedback from the pilot survey with trained interviewers, a final questionnaire was completed. All data were investigated based on their farming activities in 2011, a year previous to the survey period. In order to compare more reliable financial profitability by farming techniques, data related to livestock were excluded from the survey. The questionnaire included farm size and number of cultivated crops in arable areas. The farmers were asked about their financial returns such as agricultural revenue and subsidies, as well as their cultivation costs, including expenditures for labor, seeds, installation and management of green houses, fertilizers, pesticides and agricultural machines. The final part of the survey collected socio-economic information of the farmers such as their age, education and farming experience.

\subsection{Analytical Framework for Data Analysis}

Descriptive statistics were used to give basic information on farm households. The descriptive indicators were average values with standard deviation and frequency, which applied as independent variables in dummy or mean values of multinomial logistic regression. In addition, financial analysis was carried out to compare costs and profits among the three farming methods. The calculation is specified by the following formula: The total benefit $(E)=$ total revenue $(B)-$ total costs $(A)+$ total supported subsidy (D) (Tables 2 and 3). All costs included labor, land rent, mechanical operations, installation, management and maintenance in 2011. The farmers' net returns determined by the costs were calculated based on the revenue and subsidies obtained in 2011.

In our study, a multinomial logistic regression model was used to analyze the influence of socio-economic characteristics of farm households on different farming techniques. Multinomial logistic regression is an extended binary logistic regression model that has more than two categories of unordered outcome variables. The multinomial logistic model was estimated using normalization with one category, which is regarded as the "base category." In this study, the explanatory variable took different from one to three depending on their farming techniques. CF was used as the base category, which took one in the model. PCF took two in the explanatory variable and environmentally friendly farmers, which took three in the explanatory variable. There are several factors leading to choice decisions in the context of socio-economic background, and what we are interested in lies in the effect of each explanatory variable on individual outcomes. Therefore, we considered seven independent variables; age, education, labor of farm household, farm size, ownership, net return, and subsidy, which were simultaneously hypothesized as vital factors for the farmers' decisions.

Thus, the outcome variable can take on the variables, $j=1,2,3, \cdots j$, with $j$, a positive integer. The model explains the probability of $\mathrm{CF}(j=1)$ or $\operatorname{PCF}(j=2)$, $\operatorname{EFF}(j=3)$. The determinants associated with each category can be contrasted with the base category, which is CF in this study. In addition, this is to find out ceteris paribus changes in the elements of that affect the response probabilities, $\mathrm{p}\left(y_{i}=k \mid x_{i}\right)=\frac{\exp \left(\beta_{k} x_{i}\right)}{\sum_{j=1}^{J} \exp \left(\beta_{j} x_{i}\right)}, j=1,2,3, \ldots, J$, where $k$ is one of the sub-groups and $\mathrm{P}\left(y_{i}=k\right)$ is the probability that the farmer belongs to the subgroup and where $x_{i}$ describes farmer characteristics. In order to identify this model, constraints for the assumptions must be applied. 
A common approach is to assume that $\beta_{1}=0$ [39]. This normalization makes it possible to identify the coefficients relative to the base outcome. Applying the constraint, the model can be written as:

$$
\begin{gathered}
\mathrm{p}\left(y_{i}=k \mid x_{i}\right)=\frac{\exp \left(\beta_{k} x_{i}\right)}{1+\sum_{j=2}^{J} \exp \left(\beta_{j} x_{i}\right)}, \text { for } K>1 \\
\mathrm{p}\left(y_{i}=k \mid x_{i}\right)=\frac{1}{1+\sum_{j=2}^{J} \exp \left(\beta_{j} x_{i}\right)}
\end{gathered}
$$

The multinomial logit model utilizes maximum likelihood estimation to evaluate the probability of a categorical group using the following equation:

$\mathrm{L}\left(\beta_{2}, \ldots, \beta_{j} \mid y, X\right)=\prod_{k=1}^{j} \prod_{y_{i}=k} \frac{\exp \left(\beta_{k} x_{i}\right)}{\sum_{j=1}^{J} \exp \left(\beta_{j} x_{i}\right)}$, where $\prod y_{i}=k$ is the product over all cases for which $y_{i}=k$ [40]. Coefficients are interpreted using the relative risk ratios, which is the relative probability of $y_{i}=k$, for $\mathrm{k}>1$. The relative risk ratio is calculated without reference to the remaining two groups, PCF and EFF. This shows the underlying assumption that the model has independence from irrelevant alternatives which is regarded as binary independence [40,41]. Although statistical tests are available to confirm this proposition, the use is not recommended due to unreliable test results [42,43]. Thus, based on the recommendation by Amemiya [44], a multinomial logistic model was selected among three types of farming techniques. Overall, the model helps to indicate significant differences between PCF and EFF in the study area, relative to CF. The utilized data were analyzed by IBM SPSS statistics. The parameter estimates for the vectors that maximize the log likelihood function can be achieved [45]. Relative risk ratios, meaning probabilities of choice, can be calculated from Equation (2):

$$
\frac{\partial P_{i y}}{\partial x_{i}}=P_{i j}\left[\beta_{j}-\sum_{k=1}^{J} P_{i k} \beta_{k 0}\right] \text { for } J=1,2, \ldots J
$$

Applying Equation (2), we can observe changes in probabilities for their choice in farming techniques due to a small change in one of the farmers' characteristics, when all other independent variables are fixed [46]. The relative risk ratios for the multinomial logistic model were obtained by exponentiation of the coefficient. The exponent of the coefficients are commonly interpreted as odds ratios like logistic regression models and regarded as a marginal effect. The interpretation of the relative risk ratios is for a unit change in the predictor variable The relative risk ratio of base outcome relative to the reference group is expected to change by the factor of a respective parameter estimate, given the variables in the model are held constant.

Based on the findings of earlier studies, our study hypothesized that social and economic characteristics of farmers can be fundamental components in the adoption of farming practices. The age of farmers plays a significant role on the farmer's decision regarding conversion because younger farmers are expected to be more progressive and accepting of new farming techniques relative to older farmers [22,47]. The level of education is considered as an influencing factor. This is because well-educated farmers are more likely to utilize new advanced technologies efficiently and recognize the benefits for agricultural practices [48,49]. Farm size plays a crucial role in the conversion to EFF in terms of costs and benefits. Furthermore, higher costs of labor and time are inevitable during the conversion process [50,51]. Land ownership can be an advantage in terms of reducing the land rent cost [52]. As subsidies affect the profitability of EFF [53-55], farm net returns have also been identified as a key driver of the conversion to EFF [56,57].

Therefore, it is expected that the sign on the age variable will be negative because older farmers may set their sights on investments for farming activities over a short period of time. Education level is expected to have a positive influence on the adoption of EFF. The higher the education, the higher the probability that farmers may consider the benefits from EFF practices to recoup their costs and reap their future profits. The variable farm size was expected to have a negative sign due to the risk of income loss during the transition period and higher labor costs to convert farming techniques to EFF. The expected sign of the variable labor is negative. This is because labor is associated with additional 
costs and investments in the long term. Land ownership is expected to have a positive impact on the conversion to EFF in terms of fixed costs for farm management. It is clear that higher benefits were hypothesized to be positively associated with adoption of EFF. Obtaining a subsidy was perceived as a positive economic factor that affects farmers' choice on converting to EFF.

\section{Results}

The characteristics of the 218 farmers among three types of farming techniques are presented in Table 1. The general characteristics of the farmers are shown by descriptive statistics and the results of the one-way ANOVA. In regards to education, EFF farmers had the highest education level, with $17.6 \%$ university alumni and $25 \%$ high school graduates. The average farm size for CF was $3.4 \mathrm{ha}$. The average farm size for PCF was 4.0 ha, which included farmland area of $63.8 \%$ CF and $36.2 \%$ EFF. EFF occupied an average farm size of $2.3 \mathrm{ha}$, approximately half of the total PCF cultivated area. The age of farmers was homogenously distributed between the three groups. The group of CF was on average 55.7 years, whereas the group of partially converted farmers was on average 52.5 years old. The environmentally friendly farmers were on average 54.3 years of age. CF and PCF farmers had similar farming experience while EFF farmers had less farming experience. With respect to the EFF experience, environmentally friendly farmers had been doing EFF for nine years, about three years more experience compared to partially converted farmers. The average number of cultivated crops for PCF farmers was 5.4 ha with a range of 2-9 crops in both farming techniques. CF and EFF had similar crop numbers ( 3.4 and 3.8 crops, respectively). The findings of the ANOVA analysis showed that the three farming techniques differ significantly in their farmland size $(\mathrm{F}(218)=4.5, p<0.10))$ and average number of cultivated crops $(\mathrm{F}(218)=22.5, p<0.01))$. The distribution of main crops among the three groups is shown in Table $\mathrm{S} 1$ of appendix.

Table 2 presents the results on differences for annual average costs and benefits per farm. PCF had the largest average costs per farm with most expenditure for farm management. CF had no big difference with PCF for land rental costs. EFF had the lowest land rental costs of 1.37 million KRW and fertilizer costs of 3 million KRW. Regarding the average cost of labor, PCF had the largest wage cost of 14.70 million KRW, compared to CF and EFF. PCF had the largest fertilizer expenditure, whereas EFF had the smallest fertilizer expenditure. In terms of cost of pesticides per farm, PCF had higher pesticide expenditures than that of EFF farms. PCF had the largest other costs compared to CF and EFF.

With respect to benefits per farm household, PCF had the largest annual revenues with 61.10 million KRW compared to CF and EFF. However, the EFF net income was the largest with 26.29 million in comparison to CF and PCF. The annual net income of a PCF farm household was the smallest which was similar to CF as the PCF farmers have the highest costs for their farming activities. Although EFF had the largest subsidies from the government or province, the amount of the annual subsidy among different farming techniques had no large difference. The total annual benefit (farm net income plus subsidies) per farm was the largest for EFF, about 1.5 times greater than the benefit of $\mathrm{PCF}$ and CF.

The results of annual average costs and benefits per ha are shown in Table 3. Compared to the costs per farm (Table 2), the results for costs per ha were somewhat different. The land rental cost per ha was almost the same for CF and EFF. There was no big difference in land rental costs per ha. PCF had the smallest costs for their farmland. Average labor costs per ha were the largest for EFF, which was the highest expenditure compared of all farming techniques. CF had the lowest expenditure for labor costs. Contrary to the result of fertilizer cost per farm, the costs of fertilizer were the largest for EFF. CF had the smallest fertilizer costs and PCF was the largest. In terms of cost of pesticides per ha, CF had the highest pesticide expenditures compared to that of PCF and EFF farms. Regarding other costs, PCF farmers spent the most on other costs, whereas CF farmers spent the least. Thus, total annual cost per ha of EFF was 12.85 million KRW. The EFF farmers had the largest annual costs compared to $\mathrm{CF}$ and PCF. 
Table 1. Descriptive statistics of characteristics of farm types.

\begin{tabular}{|c|c|c|c|c|c|c|}
\hline Characteristics & Description (Unit) & $\begin{array}{c}\text { Conventional Farming } \\
\text { CF (N: 85) }\end{array}$ & $\begin{array}{l}\text { Partially Converted } \\
\text { Farming PCF (N: 65) }\end{array}$ & $\begin{array}{l}\text { Environmentally-Friendly } \\
\text { Farming EFF (N: 68) }\end{array}$ & Total (N: 218) & \\
\hline \multirow{4}{*}{ Education } & Primary School (\%) & 38.8 & 23.1 & 26.5 & 30.3 & \\
\hline & Secondary School (\%) & 35.3 & 29.2 & 30.9 & 32.1 & \\
\hline & High School (\%) & 22.4 & 41.5 & 25.0 & 28.9 & \\
\hline & University (\%) & 3.5 & 6.2 & 17.6 & 8.7 & \\
\hline $\mathrm{CF}$ & Area under management (\%) & 100 & 63.8 & NA & 35.3 & \\
\hline \multirow[t]{2}{*}{ EFF } & Area under management (\%) & NA & 36.2 & 100 & 23.3 & \\
\hline & & Mean (Std. Dev.) & & & & F-value $^{a}$ \\
\hline Farm size & (ha) & $3.4(3.8)$ & $4.0(4.2)$ & $2.2(1.8)$ & $3.2(3.5)$ & $4.5^{*}$ \\
\hline Age & (Years) & $55.7(10.2)$ & $52.5(7.9)$ & $54.3(9.4)$ & $54.3(9.3)$ & 2.3 \\
\hline Farm experience & (Years) & $29.7(14.1)$ & $29.0(11.2)$ & $25.9(14.4)$ & $28.3(13.4)$ & 1.6 \\
\hline EFF practices & (Years) & NA & $6.1(5.0)$ & $9.1(5.4)$ & $7.6(5.4)$ & NA \\
\hline Average number of crops & $(\mathrm{N})$ & $3.4(1.4)$ & $5.4(1.8)$ & $3.8(2.2)$ & $4.1(2.0)$ & $22.5^{* * *}$ \\
\hline
\end{tabular}

${ }^{a}$ Generated from one way ANOVA; ${ }^{*}$ Statistical significance at the $10 \%$ level; ${ }^{* * *}$ Statistical significance at the $1 \%$ level. 
Table 2. Difference of the three different production modes in annual costs, revenues and total benefits per farm household per year. The numbers display the mean of all farms and in brackets the standard deviation.

\begin{tabular}{|c|c|c|c|c|}
\hline & Conventional Farming CF (N: 85) & Partially Converted Farming PCF (N: 65) & Environmentally-Friendly Farming EFF (N: 68) & Total (N: 218) \\
\hline \multicolumn{5}{|c|}{ Costs $\left(10,000 \mathrm{KRW}^{(\mathrm{a})} /\right.$ farm household/year) } \\
\hline Land rent & $230(422)$ & $233(475)$ & $137(325)$ & $202(412)$ \\
\hline Labor & 942 (1884) & $1470(1898)$ & $1084(1904)$ & 1144 (1899) \\
\hline Fertilizer & $463(620)$ & $649(715)$ & $300(381)$ & 467 (602) \\
\hline Pesticides & $503(810)$ & $545(808)$ & $182(303)$ & 416 (707) \\
\hline Other costs $(b)$ & $874(1500)$ & $1390(1979)$ & $580(685)$ & $936(1508)$ \\
\hline Total cost $(\mathrm{A})$ & $3012(4055)$ & $4287(4471)$ & $2284(2957)$ & $3165(3948)$ \\
\hline \multicolumn{5}{|c|}{ Benefits (10,000 KRW ${ }^{(a)} /$ farm household/year) } \\
\hline Farm net income $(\mathrm{C}=\mathrm{B}-\mathrm{A})$ & $1828(4711)$ & $1823(3566)$ & $2629(4156)$ & $2076(4221)$ \\
\hline Subsidy (D) & $109(314)$ & $119(261)$ & $131(231)$ & $119(274)$ \\
\hline Total benefit $(E=C+D)$ & $1936(4744)$ & $1942(3609)$ & $2760(4220)$ & $2195(4266)$ \\
\hline
\end{tabular}

(a) Unit: 10,000 KRW = 7.56 euro; (b) Other costs mean extra costs for cultivating crops excepting the above mentioned costs, such as seeding, renting agricultural machinery, etc.

Table 3. The result for annual average costs, revenues and benefits standardized per hectare and year. All units are 10,000 KRW/ha/year. The numbers display the mean of all farms and in brackets the standard deviation.

\begin{tabular}{|c|c|c|c|c|}
\hline & Conventional Farming CF (N: 85) & Partially Converted Farming PCF (N: 65) & Environmentally-Friendly Farming EFF (N: 68) & Total (N: 218 \\
\hline \multicolumn{5}{|c|}{ Costs $\left(10,000 \mathrm{KRW}^{(\mathrm{a})} / \text { farm household/year }\right)^{2}$} \\
\hline Land rent & $50(68)$ & $47(59)$ & $50(100)$ & 49 (77) \\
\hline Labor & $236(389)$ & $344(389)$ & $410(610)$ & $323(473)$ \\
\hline Fertilizer & $157(187)$ & $195(203)$ & $251(410)$ & $197(281)$ \\
\hline Pesticides & 155 (181) & $144(160)$ & 109 (177) & 137 (174) \\
\hline Other costs $(\mathbf{b})$ & $303(431)$ & $540(1442)$ & $464(680)$ & $424(916)$ \\
\hline Total cost $(\mathrm{A})$ & $901(862)$ & $1270(1564)$ & $1285(1322)$ & $1131(1258)$ \\
\hline \multicolumn{5}{|c|}{ Benefits $\left(10,000 \mathrm{KRW}^{(\mathrm{a})} /\right.$ farm household/year) } \\
\hline Farm net income $(\mathrm{C}=\mathrm{B}-\mathrm{A})$ & $796(1132)$ & 817 (1764) & $1570(2183)$ & 1044 (1735) \\
\hline Subsidy (D) & $57(216)$ & 49 (139) & $89(186)$ & $65(186)$ \\
\hline Total benefit $(\mathrm{E}=\mathrm{C}+\mathrm{D})$ & $853(1200)$ & $866(1805)$ & $1658(2151)$ & $1108(1756)$ \\
\hline
\end{tabular}

(a) Unit: 10,000 KRW = 7.56 euro; ${ }^{\text {(b) }}$ Other costs mean extra costs for cultivating crops excepting the above mentioned costs, such as seeding, renting agricultural machinery, etc. 
The farming technique with the largest annual revenue per ha was EFF, which made 28.54 million KRW. The annual revenues per ha of CF and PCF were 16.97 million KRW and 20.87 million KRW, respectively. EFF had the highest annual farm net income per ha with 15.70 million KRW. The net income of CF was 7.96 million KRW and the net income of PCF was 8.17 million KRW. In the case of their subsidy per ha, EFF had the largest subsidy, which was 0.89 million KRW. PCF had the lowest amount of subsidy in their farming activities at 0.49 million KRW. Therefore, total annual benefit per ha of EFF was the highest compared to CF and PCF. The difference of the benefits between EFF and other farming techniques was about double. The total benefit of CF and PCF was slightly different, as the total benefits of CF and PCF were 8.53 million KRW and 8.66 million KRW, respectively.

The result of multinomial logistic regression model is presented in Table 4 . Based on the $\mathrm{R}^{2}$ pseudo statistics and Chi-Square test, this multinomial logistic regression model shows that the estimated model is well fitted and statistically significant at the $1 \%$ level. It is important to note that likelihood ratio statistics indicated by $X^{2}$ statistics (52.57) are highly significant $(p=0.0001)$, suggesting that this makes the estimates obtained good enough for running this analysis. The Log likelihood value suggests that the model has adequately explained the farmers' choices on farming techniques. In all cases, the estimated coefficients are compared with the base category of conventional farming. Conventional farmers occupied $39.0 \%$ of our survey. The partially converted farmers accounted for $29.8 \%$, whereas environmentally friendly farmers accounted for $31.2 \%$ of the sample.

Table 4. Coefficient estimates and standard errors in parentheses for multinomial logistic regression model.

\begin{tabular}{|c|c|c|c|c|}
\hline \multirow{2}{*}{ Variable } & \multicolumn{2}{|c|}{ Partially Converted Farming PCF } & \multicolumn{2}{|c|}{ Environmentally Friendly Farming EFF } \\
\hline & Coeff. & Std. Error & Coeff. & Std. Error \\
\hline Intercept & -1.212 & 1.293 & -1.760 & 1.306 \\
\hline Age & -0.103 & 0.224 & 0.129 & 0.224 \\
\hline Education ${ }^{(1)}$ & $0.353 *$ & 0.188 & 0.354 * & 0.190 \\
\hline Farm size & 0.015 & 0.050 & $-0.219 * *$ & 0.104 \\
\hline Labor of farm household ${ }^{(2)}$ & 0.247 & 0.437 & 0.361 & 0.436 \\
\hline Land ownership of land ${ }^{(3)}$ & 0.195 & 0.382 & -0.586 & 0.391 \\
\hline Subsidy $(4)$ & $1.005^{* * *}$ & 0.356 & $1.649^{* * *}$ & 0.378 \\
\hline Farm net income & -0.035 & 0.049 & 0.047 & 0.054 \\
\hline
\end{tabular}

Number of observations 218; Pseudo R ${ }^{2}$ : Cox and Snell 0.21; Nagelkerke 0.24; McFadden 0.11; LR chi²(12) 52.57; Log likelihood -211.65 .

Notes: ${ }^{*}$ significant at $10 \% ;{ }^{* *}$ significant at $5 \% ;{ }^{* *}$ significant at $1 \% .{ }^{(1)} 0=$ no education; $1=$ primary education;

$2=$ secondary education; $3=$ high school; $4=$ college and university; ${ }^{(2)} 0=$ farmers who had no farm laborer,

$1=$ farmers who had own farm laborers; ${ }^{(3)} 0=$ farmers who rented farmland, $1=$ farmers who possess farmland;

(4) 0 = farmers who did not receive subsidy, 1 = farmer who received subsidy.

The estimates for PCF and EFF relative to CF were observed differently with positive signs across the groups. The result showed that age, labor of farm household, land ownership, and farm net income were not statistically significant. However, education level, farm size and subsidy were significantly related to the farmers' choice on farming techniques. The coefficient for education level was statistically significant and positively correlated to the probability on PCF and EFF at $10 \%$ significance level, relative to CF. Farm size was found to be statistically significant at $5 \%$ significance level and positive correlation with the probability of adopting EFF, whereas farm size was not significantly related to the PCF. The coefficient for subsidy was highly significant for both farm groups relative to the base outcome at the $1 \%$ significance level. This indicates a strong positive relationship between the subsidy and the likelihood of farmers' adoption of PCF and EFF relative to CF. Therefore, these results show that as farmers' education level and subsidy increase, the likelihood of farmers' choice for PCF and EFF increases. Moreover, as the farm size decreases the probability of farmers' choice on EFF increases.

The relative risk ratios of the multinomial logistic model are shown in Table 5. This result was obtained by the exponential of the coefficients, which provide estimates of the relative risks. The result showed that one unit change in education level had no significant differences between PCF and EFF, 
whereas relative risk ratios of the variable increased. It was expected that the relative risk of practicing PCF and EFF over CF (base category) increased by Exp. $(0.35)=1.42$. If the farmers would increase their education level by one unit, the relative risk for PCF and EFF relative to CF would be expected to increase by the determinants of 1.42, given other variables in the model are held constant. With regard to farm size for their cultivated land, the relative risk ratio for EFF relative to CF would be expected to decrease by a factor of 0.80 given the other variables in the model are held constant. As farm size is negatively related to the EFF, an increase in farm size by one unit reduces the likelihood that a farmers' chose EFF by $80.3 \%$. In addition, the relative risk ratios of the variable subsidy for PCF and EFF were 2.73 and 5.20, respectively. Given a one unit increase in subsidy, the relative risk of having adopted PCF and EFF would be 2.73 times and 5.20 times, respectively, more compared with the CF. This means farmers who received subsidies were more likely to choose PCF and EFF by a factor of 2.73 and 5.20, respectively, as partially converted and environmentally friendly farmers require subsides for the adoption.

Table 5. The results of marginal effects by multinomial logistic regression model.

\begin{tabular}{|c|c|c|}
\hline \multirow{2}{*}{ Variable } & \multicolumn{2}{|c|}{ Marginal Effect ${ }^{(1)}$} \\
\hline & Partially Converted Farming PCF & Environmentally Friendly Farming EFF \\
\hline Age & 0.902 & 1.138 \\
\hline Education & $1.423 *$ & $1.425 *$ \\
\hline Farm size & 1.015 & $0.803^{* *}$ \\
\hline Labor of farm household & 1.280 & 1.435 \\
\hline Land ownership & 1.216 & 0.556 \\
\hline Subsidy & $2.733^{* * *}$ & $5.200^{* * *}$ \\
\hline Farm net income & 0.966 & 1.048 \\
\hline
\end{tabular}

\section{Discussion}

Organic farming is one of several advanced farming techniques considered to provide environmental benefits and fit within the spectrum of sustainable economic development. In environmentally sensitive areas, organic farming supports water conservation as it reduces the rate of damaging runoff coming from insensitively managed farming. The national government of South Korea has adopted environmentally friendly farming (EFF) in order to move towards sustainable agriculture. The adoption rate of EFF in South Korea is, however, still low as it is in other developed and developing countries. Additionally, the selected area of our study is relative to other regions in South Korea more important with respect to farmers' decision on practices for watershed protection. Historically, during the monsoon period, in the selected area in Gangwon Province, the excess use of chemical fertilizers and pesticides has caused the permeation of these chemicals into surface waters, leading to negative effects on the water quality of the Soyang watershed, a main source of drinking water of South Korea. Thus, in order to identify which farming techniques are profitable and what factors influence farmers' choices, we compared the costs and benefits of various farming techniques and examined socio-economic factors affecting adoption of farming techniques, based on survey data. The findings of this study can contribute to the promotion and development of organic farming in South Korea. In addition, this study can be developed into similar studies in other Asia countries and in environmentally sensitive areas using multi-year data.

\subsection{Environmentally Friendly Farming in South Korea}

In South Korea, agriculture can be generally categorized into conventional farming (CF) and EFF. However, in this field survey, we found that partially converted farming (PCF) is emerging. Accordingly, the survey was conducted with the three types of farming techniques, namely $\mathrm{CF}$, 
PCF and EFF. Moreover, the study site was a part of the nonpoint pollution sources management areas (Hongcheon-Gun, Inje-Gun, and Yanggu-Gun) within the catchment of the Soyang watershed in Gangwon Province, South Korea. The management area for nonpoint pollution sources was designated to prevent water quality degradation due to eroded soil from agricultural areas in this province. The Soyang catchment of this province has an important role in the supply of potable water for the metropolitan area Seoul. Despite the promotion of EFF by the local authorities and government of South Korea, the Gangwon Province contained a low certified area of EFF. Thus, with the importance of the study sites, this research aimed to identify which farming technique is more profitable by financial analysis and to examine which factors affect the adoption of farming techniques in South Korea using multinomial logistic regression.

\subsection{Cost and Benefits of the Three Farming Techniques}

The results of the financial analysis showed that the EFF labor costs per ha were higher than CF and PCF. This is in line with previous studies that have shown that organic farming has more labor requirements than $\mathrm{CF}[9,58]$. In our study, fertilizer costs for EFF per ha were higher than for other farming techniques. This finding is inconsistent with the result of Sgroi et al. [59], who found that CF had higher fertilizer costs when compared to organic one. The reason for the higher fertilizer costs in this area might be caused by the use of low quality organic fertilizer, which led not only to less crop production but also caused higher costs. Due to a short history of EFF in South Korea, the adequate production, distribution and quality assurance of organic fertilizer are problematic and tend to increase their production costs [26]. This is in line with the studies of Bernal et al. [60] who mentioned that an increase in yields would require high compost quality and improved quality of organic fertilizer. Therefore, in order to promote the EFF, proper quality and quantity of fertilizers including different nutrients and ingredients should be investigated for the various crop choices reflected in different districts. An alternative way to reduce production costs substantially would be improved soil fertility, by promoting compost and nutrient management strategies. Considering water quality degradation of the catchment from soil erosion and nutrient run-off in this study area, the moderate application of fertilizers, dependent on the local geographical conditions, is required to protect the fresh water quality.

With regard to the benefits, financial net returns per farm and ha of EFF were higher compared to $\mathrm{CF}$ and PCF, when considering the total expenses, annual income and subsidies. This is coherent with the results of Kristiansen et al. [61], Delbridge et al. [16], Patil et al. [7] and Salvioni et al. [28] who showed the profitability of organic farming. In the benefit of EFF, the higher revenues per ha might be due to the price premium of the produce. This is consistent with findings of studies which indicated that the higher net returns can be attributed to the premium price of organic products $[62,63]$. In South Korea, with the certification system of EFF, a price premium incentivizes the farmers into the EFF products market like in other developed countries [64]. The price premium was about 1.2 2.0 times depending on different crop choices [26]. In the study area, we found with the personal interviews, that some farmers had contracts with a big market in the capital city as they guarantee relatively higher selling prices. Therefore, despite higher total costs per ha of EFF, compared to those of CF and PCF, the EFF was more financially attractive in this area with higher price premiums of the products. The results associated with profits in our study area were in contrast with the study by Kim et al. [26] that also surveyed in South Korea in terms of different crops in various provinces; they found that EFF cultivation of rice, vegetable and fruits had higher costs and lower benefits due to a transition period which caused low yields and hence income loss. Even though our work provides a number of interesting results, it should be extended in the future by interviewing more households in different areas of South Korea in different years so that the results can be generalized and are more robust. Thus, we suggest that future studies should survey more data in multiple years. 


\subsection{Factors Influencing the Adoption of Partially Converted Farming PCF and Environmentally Friendly Farming EFF}

In our survey, most of the farmers that were interviewed as representatives of their farm households were male. With respect to the education level in our survey, EFF farmers were found to be better educated than the CF and PCF counterparts. Among the three agricultural groups, age differed only little, between one to three years on average. Among the farming techniques, the farming experience between CF and PCF was almost identical while the standard deviation for CF experience was slightly larger than the farming experience of PCF. Regarding the green farming experience, PCF farmers had less experience by about three years, compared with the EFF farmers. Farm size and number of crops were statistically significant as shown by ANOVA. The EFF had the smallest cultivated area, whereas PCF had largest farm size, which is in line with the results of the largest number of cultivated crops in PCF. PCF farms had a higher cultivated farm area per farm household than the South Korean average (1.23 ha in 2010).

To identify influencing factors determining the three farming techniques multinomial logistic regression (MNL) was used. Before implementing a variance inflation test was implemented to consider the risk of multicollinearity between selected explanatory variables. While the estimates of the parameter in MNL model gives the direction of the effect of predictors on the explanatory variable, the marginal effects in the model offer the actual magnitude of change in probability. Thus, in MNL, we showed the coefficients and marginal effects indicating relative risk ratios (Tables 4 and 5) are significant determinants that have an influence on the likelihood of the farmers' choice on farming techniques. The MNL model included important socio-economic variables such as age, education level, farm size, labor, land ownership, subsidies and net returns per farm household. Although we considered both subsidies and net income in this model simultaneously, the interpretation of the effects of these factors should be done with care, since they might be a causality problem due to an econometric simultaneity issue. The results showed that age, whether or not farmers have laborers and ownership over their farmland, and net farm income were not significantly related to any of the three farming techniques.

However, as expected, education level of farmers was positively correlated to PCF and EFF. This result is hardly surprising as more educated farmers would have acquired the knowledge and would adopt advanced techniques relatively easily. This implied that the higher the education of the farmers, the greater the likelihood that farmers choose to adopt PCF and EFF, by 1.42 times. This finding confirms that of Weir and Knight [48], and Lapar and Ehui [49] who argue that an increase in farmers' education level increases the likelihood of adopting advanced farming techniques.

Moreover, farm size had a negative and significant relationship with EFF. This implies that the farm size decreases the tendency of adopting EFF by 0.80 . Our finding supports the previous study by Khaledi et al. [29] who found that farmers with smaller farmland can more easily manage their fields to certified regulations. In addition, relatively small farmlands could be easier to manage within the regulations and standards of organic farming. This is inconsistent with the results of Karki et al. [50], showing that larger farm size is likely to adopt organic farming. This means the larger farm size has the potential for higher costs in labor and inevitable larger income loss during their transition period after they adopt EFF. In addition, according to Padel [65], the conventional and partially converted farmers could adopt organic farming later. The result is in line with Läpple and Rensburg [5] suggesting that larger farms are less likely to adopt organic farming which causes more intensive labor and is associated with higher costs and relatively higher risks.

The variable indicating whether or not farmers receive subsidies had a highly positive influence on the probability of the farmers' adoption of PCF and EFF. As a result of marginal effects of subsidies for PCF and EFF, the relative risk ratio for PCF and EFF relative to CF would be expected to increase by a factor of 2.73 and 5.20 , respectively. The result demonstrates that receiving subsidies is the most significant positive influence on farmers' decisions. Moreover, similar studies found a positive relationship between the conversion process as an institutional factor $[66,67]$. This revealed that the 
subsidy can be considered as a key factor to encourage farmers to convert to EFF and expand arable land area of EFF [68]. Considering the importance of the subsidy, it should be noted that the direct payment program for EFF in South Korea is important to stimulate the farmers to change their farming techniques to EFF. In order to extend the EFF, the improvement of direct payment program for EFF is required as an incentive for compensating the income loss of environmentally friendly farmers during their transition period. The improvement measure to enhance the program of direct payment could be the unit price adjustment, changes in the payment period and the compensation by crop types [69].

\subsection{Partially Converted Farming PCF in Our Study}

The results of the characteristics of PCF indicated that the partially converted farmers had the largest farm size and the highest number of crops. Although some PCF farmers went through the transition period in order to adopt EFF and the higher costs for implementing PCF, they continued to practice the PCF. This can play an important role in extending agricultural land of EFF. Therefore, viewed this way, the partially converted farmers in the districts might be considered as a bottleneck in promotion of EFF. Monitoring the developments of the agricultural sector among different types of farming techniques could be a key issue in the promotion policy of the local and national government.

Furthermore, throughout the interviews with farmers in the field survey conducted for this research, we found that partially converted farmers exist. The PCF is not officially recorded by the government as PCF farmers might be normally grouped in CF or in EFF under official data of the government. Therefore, extra studies related with PCF might be needed. Specifically, regarding the PCF, there is still little research on how PCF has developed, how they affect the market and how they influence the decision of other farmers. Accordingly, several questions occur: Can they be considered as a potential barrier to promote EFF, or are they in a transition period towards EFF? How high is the possibility that they return to CF or persevere with PCF? In this respect, PCF is especially important, as these farmers have the potential to compare both farming techniques and output of the sectors.

\section{Conclusions and Policy Recommendations}

The process of moving toward sustainability through organic farming has led to the emergence of partially converted farming in South Korea. These new partially converted farmers are not officially recorded and not investigated in South Korea. Partially converted farms could be a potential barrier for promotion of organic farming. Therefore, to extend organic agricultural land area, an up-to-date official database for partially converted farmers including production costs and revenues should be established in each district. In addition, while environmentally friendly farming is more profitable in our study area, the probability of higher costs is still remaining and could be one of the obstacles to extending organic agricultural land. Therefore, the government should provide more detailed support for reducing production costs. In particular, higher fertilizer costs are required in order to invest in improvement of the quality and investigation of the appropriate quality for organic fertilizers. Ultimately, in order to promote compliance with international standards of organic farming, improved measures for enhancing fertilizer management should be implemented by the government. Farmers' choice behavior can be driven by the utility perceived and net benefit from farming techniques. This is beyond the aim of the current study, which has focused on financial profitability and determinants affecting their decisions. Further research would be necessary to investigate farmers' perception and behavior reflecting different local conditions. Considering varying socio-economic characteristics and different factors affecting farming techniques in different regions, research projects on promotion of organic farming would be beneficial to design more targeted policy for sustainable agriculture.

Supplementary Materials: The following are available online at www.mdpi.com/2071-1050/8/7/704/s1. Figure S1: Distribution of costs per farm including outliers (N: 224), Figure S2: Distribution of benefits (red) per farm including outliers (N: 224), Figure S3: Distribution of costs per ha including outliers (N: 224), Figure S4: Distribution of benefits (yellow) per ha including outliers (N: 224), Table S1: Total and organic cultivated area 
and the consumed quantity per ha of chemical fertilizers and pesticide in South Korea, Table S2: Main crops in percentage of farmers cultivating it and its average farm size split by farming techniques (Conventional farming CF, Partially Converted farming PCF and Environment-Friendly Farming EFF).

Acknowledgments: This study was carried out as part of the International Research Training Group TERRECO (GRK 1565/1) funded by the Deutsche Forschungsgemeinschaft (DFG) at the University of Bayreuth, Germany and the National Research Foundation of Korea (NRF) at Kangwon National University, Chuncheon, South Korea. We would like to thank Joe Premier for providing English corrections. This publication was funded by the German Research Foundation (DFG) and the University of Bayreuth in the funding programme Open Access Publishing.

Author Contributions: All authors developed the research design and contributed to the writing of the paper. Saem Lee collected the data and did the statistical analysis. Trung Thanh Nguyen, Patrick Poppenborg, Hio-Jung Shin and Thomas Koellner contributed to the data analysis, and reviewed and edited the manuscript.

Conflicts of Interest: The authors declare no conflict of interest.

\section{References}

1. Stanhill, G. The comparative productivity of organic agriculture. Agric. Ecosyst. Environ. 1990, 30, 1-26. [CrossRef]

2. Aldanondo-Ochoa, A.M.; Casasnovas-Oliva, V.L.; Arandia-Miura, A. Environmental efficiency and the impact of regulation in dryland organic vine production. Land Use Policy 2014, 36, 275-284. [CrossRef]

3. Argyropoulos, C.; Tsiafouli, M.A.; Sgardelis, S.P.; Pantis, J.D. Organic farming without organic products. Land Use Policy 2013, 32, 324-328. [CrossRef]

4. Stolze, M.; Lampkin, N. Policy for organic farming: Rationale and concepts. Food Policy 2009, 34, $237-244$. [CrossRef]

5. Läpple, D.; Rensburg, T.V. Adoption of organic farming: Are there differences between early and late adoption? Ecol. Econ. 2011, 70, 1406-1414. [CrossRef]

6. Leifeld, J. How sustainable is organic farming? Agric. Ecosyst. Environ. 2012, 150, 121-122. [CrossRef]

7. Patil, S.; Reidsma, P.; Shah, P.; Purushothaman, S.; Wolf, J. Comparing conventional and organic agriculture in Karnataka, India: Where and when can organic farming be sustainable? Land Use Policy 2014, 37, 40-51. [CrossRef]

8. Uematsu, H.; Mishra, A.K. Organic farmers or conventional farmers: Where's the money? Ecol. Econ. 2012, 78, 55-62. [CrossRef]

9. Lobley, M.; Butler, A.; Reed, M. The contribution of organic farming to rural development: An exploration of the socio-economic linkages of organic and non-organic farms in England. Land Use Policy 2009, 26, 723-735. [CrossRef]

10. Scialabba, N.E.-H. Organic Agriculture and Food Security; FAO: Rome, Italy, 2007.

11. Jeong, H.-K.; Moon, D.-H. Response Strategy to the Abolishment of Low-Pesticide Agricultural Product Certification; Korea Rural Economic Institute (KREI) Report; Korea Rural Economic Institute: Seoul, Korea, 2013. (In Korean)

12. Ministry of Agriculture, Food and Rural Affairs (MAFRA). The 3rd Environment-Friendly Agriculture Promotion 5-Year Plan; Environment-Friendly Agriculture Division: Sejong-si, Korea, 2013. (In Korean)

13. The World of Organic Agriculture-Statistics and Emerging Trends 2016. Available online: https://shop.fibl. org/en/article/c/statistics/p/1698-organic-world-2016.html (accessed on 1 March 2016).

14. Rattanasuteerakul, K.; Thapa, G.B. Status and financial performance of organic vegetable farming in northeast Thailand. Land Use Policy 2012, 29, 456-463. [CrossRef]

15. Acs, S.; Berentsen, P.; Huirne, R.; Van Asseldonk, M. Effect of yield and price risk on conversion from conventional to organic farming. Aust. J. Agric. Resour. Econ. 2009, 53, 393-411. [CrossRef]

16. Delbridge, T.A.; Coulter, J.A.; King, R.P.; Sheaffer, C.C. A Profitability and risk analysis of organic and high-input cropping systems in Southwestern Minnesota. In Proceedings of the Agricultural and Applied Economics Association, Annual Meeting, Denver, CO, USA, 25-27 July 2010.

17. Offermann, F.; Nieberg, H. Economic Performance of Organic Farms in Europe; Organic Farming in Europe: Economics and Policy; University of Hohenheim: Stuttgart, Germany, 2000.

18. Mahoney, P.R.; Olson, K.D.; Porter, P.M.; Huggins, D.R.; Perillo, C.A.; Kent Crookston, R. Profitability of organic cropping systems In Southwestern Minnesota. Renew. Agric. Food Syst. 2004, 19, 35-46. [CrossRef] 
19. Oude Lansink, A.; Jensma, K. Analysing profits and economic behaviour of organic and conventional dutch arable farms. Agric. Econ. Rev. 2003, 4, 19-31.

20. Padel, S. Conversion to Organic Farming: A typical example of the diffusion of an innovation? Sociol. Ruralis 2001, 41, 40-61. [CrossRef]

21. Sarker, M.A.; Itohara, Y.; Hoque, M. Determinants of adoption decisions: The case of organic farming in Bangladesh. Ext. Farming Syst. J. 2010, 5, 39-46.

22. Mabuza, M.L.; Sithole, M.M.; Wale, E.; Ortmann, G.F.; Darroch, M.A.G. Factors influencing the use of alternative land cultivation technologies in Swaziland: Implications for smallholder farming on customary Swazi Nation Land. Land Use Policy 2013, 33, 71-80. [CrossRef]

23. Ullah, A.; Shah, S.N.M.; Ali, A.; Naz, R.; Mahar, A.; Kalhoro, S.A. Factors affecting the adoption of organic farming in Peshawar-Pakistan. Agric. Sci. 2015, 6, 587-593. [CrossRef]

24. Hwang, J.-H. A Study on the marketing strategy of environment-friendly agricultural products. Korean J. Org. Agric. 2009, 17, 327-345.

25. Kim, H.-J. The Features of eco-agricultural producers, producers' organization and the potentialities of alternative agro-food system: A case study of the Pulmu Life Cooperative. Korean Soc. Sci. Res. Rev. 2008, 24, 185-212.

26. Kim, C.-G.; Jeong, H.-K.; Moon, D.-H. Production and Consumption Status and Market Prospects for Environment-Friendly Agri-foods; Korea Rural Economic Institute (KREI): Seoul, Korea, 2012. (In Korean)

27. Nieberg, H.; Offermann, F.; Zander, K. Organic Farms in a Changing Policy Environment: Impacts of Support Payments; EU-Enlargement and Luxembourg Reform; University of Hohenheim: Stuttgart, Germany, 2007.

28. Salvioni, C.; Aguglia, L.; Borsotto, P. The sustainability for an organic sector under transition: An empirical evaluation for Italy. In Proceedings of the 10th European IFSA Symposium, Aarhus, Denmark, 1-4 July 2012.

29. Khaledi, M.; Weseen, S.; Sawyer, E.; Ferguson, S.; Gray, R. Factors influencing partial and complete adoption of organic farming practices in Saskatchewan, Canada. Can. J. Agric. Econ. 2010, 58, 37-56. [CrossRef]

30. Thapa, G.B.; Rattanasuteerakul, K. Adoption and extent of organic vegetable farming in Mahasarakham province, Thailand. Appl. Geogr. 2011, 31, 201-209. [CrossRef]

31. Mondal, S.; Haitook, T.; Simaraks, S. Farmers' knowledge, attitude and practice toward organic vegetables cultivation in Northeast Thailand. Kasetsart J. Soc. Sci. 2014, 35, 158-166.

32. Province, Gangwon Statistical Yearbook, Gangwon Province, 2013. Available online: http://stat.gwd.go.kr/ sub/sub03_10.asp\# (accessed on 12 December 2015). (In Korean).

33. Jeon, M. Device for Reducing Muddy Water in the Watershed of Soyang Dam; Research Institute for Gangwon: Gangwon Province, Korea, 2008. (In Korean)

34. Jeon, M. An Institutional Plan to Manage Areas in Gangwon Province that Are Vulnerable to Nonpoint Source Pollution; Research Institute for Gangwon: Gangwon Province, Korea, 2015. (In Korean)

35. Poppenborg, P.; Koellner, T. Do attitudes toward ecosystem services determine agricultural land use practices? An analysis of farmers' decision-making in a South Korean watershed. Land Use Policy 2013, 31, 422-429. [CrossRef]

36. Arnhold, S.; Lindner, S.; Lee, B.; Martin, E.; Kettering, J.; Nguyen, T.T.; Koellner, T.; Ok, Y.S.; Huwe, B. Conventional and organic farming: Soil erosion and conservation potential for row crop cultivation. Geoderma 2014, 219-220, 89-105. [CrossRef]

37. Nguyen, T.T.; Ruidisch, M.; Koellner, T.; Tenhunen, J. Synergies and tradeoffs between nitrate leaching and net farm income: The case of nitrogen best management practices in South Korea. Agric. Ecosyst. Environ. 2014, 186, 160-169. [CrossRef]

38. Hoang, V.-N.; Nguyen, T.T. Analysis of environmental efficiency variations: A nutrient balance approach. Ecol. Econ. 2013, 86, 37-46. [CrossRef]

39. Long, J.S. Regression Models for Categorical and Limited Dependent Variables; Sage Publications: Thousand Oaks, CA, USA, 1997.

40. Tse, Y.K. A diagnostic test for the multinomial logit model. J. Bus. Econ. Stat. 1987, 5, 283-286.

41. Hausman, J.; McFadden, D. Specification tests for the multinomial logit model. Econometrica 1984, 52, 1219-1240. [CrossRef]

42. Cheng, S.; Long, J.S. Testing for IIA in the multinomial logit model. Sociol. Method. Res. 2007, 35, 583-600. [CrossRef] 
43. Long, J.S.; Freese, J. Regression Models for Categorical Dependent Variables Using Stata, 2nd ed.; Stata Press: College Station, TX, USA, 2006.

44. Amemiya, T. Qualitative response models: A survey. J. Econ. Lit. 1981, 14, 1483-1536.

45. Greene, W.H. Econometric Analysis, 6th ed.; Prentice-Hall: Upper Saddle River, NJ, USA, 2008.

46. Goktolga, Z.G.; Bal, S.G.; Karkacier, O. Factors effecting primary choice of consumers in food purchasing: The Turkey case. Food Control 2005, 17, 884-889. [CrossRef]

47. Bullock, R.; Mithöfer, D.; Vihemäki, H. Sustainable agricultural intensification: The role of cardamom agroforestry in the East Usambaras, Tanzania. Int. J. Agric. Sustain. 2013, 12, 109-129. [CrossRef]

48. Weir, S.; Knight, J. Adoption and Diffusion of Agricultural Innovations in Ethiopia: The Role of Education; Oxford University: Oxford, UK, 2000.

49. Lapar, M.L.A.; Ehui, S.K. Factors affecting adoption of dual-purpose forages in the Philippine uplands. Agric. Syst. 2004, 81, 95-114. [CrossRef]

50. Karki, L.; Schleenbecker, R.; Hamm, U. Factors influencing a conversion to organic farming in Nepalese tea farms. J. Agric. Rural Dev. Trop. Subtrop. 2011, 112, 113-123.

51. Adesina, A.A.; Mbila, D.; Nkamleu, G.B.; Endamana, D. Econometric analysis of the determinants of adoption of alley farming by farmers in the forest zone of southwest Cameroon. Agric. Ecosyst. Environ. 2000, 80, 255-265. [CrossRef]

52. Ayuya, O.A.; Waluse, S.K.; Gido, O.E. Multinomial logit analysis of small-scale farmers' choice of organic soil management practices in Bungoma county, Kenya. Curr. Res. J. Soc. Sci. 2012, 4, 314-322.

53. Flaten, O.; Lien, G.; Ebbesvik, M.; Koesling, M.; Valle, P.S. Do the new organic producers differ from the 'old guard'? Empirical results from Norwegian dairy farming. Renew. Agric. Food Syst. 2006, 21, 174-182. [CrossRef]

54. Isin, F.; Cukur, T.; Armagan, G. Factors affecting the adoption of the organic dried fig agriculture system in Turkey. J. Appl. Sci. 2007, 7, 748-754.

55. Bowman, M.S.; Zilberman, D. Economic factors affecting diversified farming systems. Ecol. Soc. 2013. [CrossRef]

56. Koesling, M.; Flaten, O.; Lien, G. Factors influencing the conversion to organic farming in Norway. International Journal of Agricultural Resources. Gov. Ecol. 2008, 7, 78-95.

57. Pietola, K.; Lansink, A. Farmer response to policies promoting organic farming technologies in Finland. Eur. Rev. Agric. Econ. 2001, 28, 1-15. [CrossRef]

58. Lampkin, N.H.; Padel, S. Conversion to Organic Farming: An International Perspective; Cab International: Wallingford, UK, 1994; pp. 295-313.

59. Sgroi, F.; Candela, M.; Trapani, A.; Foderà, M.; Squatrito, R.; Testa, R.; Tudisca, S. Economic and financial comparison between organic and conventional farming in sicilian lemon orchards. Sustainability 2015, 7, 947-961. [CrossRef]

60. Bernal, M.P.; Alburquerque, J.A.; Moral, R. Composting of animal manures and chemical criteria for compost maturity assessment. A Review. Bioresour. Technol. 2009, 100, 5444-5453. [CrossRef] [PubMed]

61. Kristiansen, P.; Merfield, C.H. Overview of organic agriculture. In Organic Agriculture: A Global Perspective; Kristiansen, P., Ed.; CSIRO: Clayton South, Australia, 2006; pp. 1-19.

62. Halpin, D.; Brueckner, M. The retail pricing, labelling and promotion of organic food in Australia. The Australian organic industry: A profile; Department of Agriculture, Fisheries, and Forestry: Canberra, Australia, 2004.

63. Characteristics of Conventional and Organic Apple Production in the United States. Available online: http: //www.ers.usda.gov/publications/fts-fruit-and-tree-nuts-outlook/fts34701.aspx (accessed on 22 February 2016).

64. The World of Organic Agriculture-Statistics and Emerging Trends 2007. Available online: http://orgprints. org/10506/ (accessed on 12 March 2015).

65. Padel, S. Conversion to Organic Milk Production: The Change Process and Farmers Information Needs. Ph.D. Thesis, University of Wales, Aberystwyth, UK, 2001.

66. Tzouramani, I.; Liontakis, A.; Sintori, A.; Alexopoulos, G. Assessing organic cherry farmers' strategies under different policy options. Mod. Econ. 2014, 5, 313-323. [CrossRef]

67. Lohr, L.; Salomonsson, L. Conversion subsidies for organic production: Results from Sweden and lessons for the United States. Agric. Econ. 2000, 22, 133-146. [CrossRef] 
68. Jánský, J.; Živělová, I. Subsidies for the organic agriculture. Agric. Econ. Czech 2007, 53, 393-402.

69. Kim, C.-G.; Jeong, H.-K.; Jang, J.-G.; Kwon, H.-M.; Moon, D.-H. Improving Direct Payment Systems for Environment-Friendly Agriculture and Introducing Environmental Cross Compliance Program; Korea Rural Economic Institute: Seoul, Korea, 2010. (In Korean) 